\title{
The impact of COVID-19 on the labour market for persons affected by Hansen's disease
}

\author{
Ana Carolina Corrêa de Sousa ${ }^{\text {a }}$ \\ ${ }^{a}$ Movement for the Integration of Persons Affected by Hansen's Disease \\ (MORHAN), Brazil \\ e-mail: anacarolinacsousa@hotmail.com
}

Submitted 3 July 2021; Accepted 7 August 2021

\begin{abstract}
Summary The COVID-19 pandemic impacted the whole world, affecting the economy of many societies, increasing poverty and inequalities. The lockdown measures heavily affected vulnerable social groups, including persons affected by Hansen's disease $(\mathrm{PaHd})$ and their families. Stigma, late diagnosis and related disability make PaHd a population in a situation of vulnerability. Poor sanitary and socio-economic conditions, lower levels of education and food insecurity are risk markers for Hansen's disease.

Before COVID-19, PaHd were refused employment or lost their jobs due to physical impairment or discrimination. Job losses worldwide are hitting hardest on poor and vulnerable populations, therefore pushing millions of people to extreme poverty.

Hansen's disease, also known as leprosy, is only endemic in the poorest areas of the world. Although specific data regarding PaHd are scarce, we traced a parallel between the impact of the current pandemic on the labour market on various excluded and marginalized populations, such as persons with disabilities and PaHd. Our objective was to understand the current scenario and also to gather strategies and good practices to guarantee and promote the right to work as an instrument of inclusion and social advancement, to break the cycle of poverty for $\mathrm{PaHd}$.
\end{abstract}

Keywords: Hansen's disease, leprosy, poverty, COVID-19, employment

\section{Introduction}

The burden of the COVID-19 pandemic, together with the lockdown measures aiming to stop the spread of the virus, severely affected many societies and economies and will most likely increase poverty and inequalities. The greater impact of the lockdown has been on vulnerable social groups, including persons affected by Hansen's disease (PaHd) and their families. The most common difficulties have been related to access to the healthcare system and the maintenance of their livelihood. PaHd with related Hansen's disease reactions could be at high risk of COVID-19 infection. Hansen's disease can be cured, however the damage 
to the nerves, skin and limbs are irreversible and even after treatment, many persons affected can show deformities, disabilities and amputated limbs.

With the shift of hospital priorities towards COVID-19 responses, access to health care became limited, specially for rehabilitation services; therefore the incidence of Hansen's disease reactions is also likely to increase, thus raising the number of PaHd with disability, generating an impact not only on the economy but on the livelihood of these people and their families that already suffer from stigma, discrimination and are still being marginalized by the modern society. Difficulties in employment are one of the many barriers for PaHd due to physical impairments and the stigma towards the disease. Discrimination issues keep $\mathrm{PaHd}$ from getting salaried work. A substantial proportion of PaHd with related disability is unemployed or does informal work, to maintain the livelihood of their families. Women are disproportionally affected by unemployment. ${ }^{1-3}$

The COVID-19 pandemic is estimated to add 88 million people to the already 115 million people in situations of extreme poverty, the majority in countries with high poverty rates. Job losses worldwide are hitting hardest on poor and vulnerable populations therefore pushing millions of people into extreme poverty. Hansen's disease, also known as leprosy is only endemic in the poorest areas of the world. Many families cannot afford or access enough food, which can lead to malnutrition that lowers the immunity, making people more vulnerable to infectious diseases. Therefore, malnutrition is an aspect of poverty that plays an important role in the development of clinical signs of leprosy. ${ }^{1,4-8}$

Stigma, late diagnosis and related disability make $\mathrm{PaHd}$ a population in a situation of vulnerability and inequity. Increased age, poor sanitary and socio-economic conditions, lower levels of education and food insecurity are risk markers for Hansen's disease. These findings point to a consistent relationship between Hansen's disease and unfavourable economic circumstances, so that $\mathrm{PaHd}$ are a socially vulnerable group in high-burden countries. Although specific data regarding PaHd are scarce, we can trace a parallel between the impact of the current pandemic on the labour market on all excluded and marginalized populations, such as persons with disabilities and PaHd. Our objective was to understand the current scenario and also to gather strategies and good practices to guarantee and promote the right to work as an instrument of inclusion and social advancement, to break the cycle of poverty for PaHd.

The policies, funds and efforts to reduce the impact of the current pandemic should be also geared towards PaHd. Before COVID-19 PaHd were refused employment or lost their jobs due physical impairment or discrimination with consequential financial burden that led to poverty affecting their livelihood. Many persons affected live in conditions of extreme poverty with few opportunities of earning an income, thus turning to informal underpaid jobs and or to begging as a last resort. Short term, some countries are providing monetary assistance to those most in need, for example, social protection payments to those who have recently became unemployed due to the COVID-19 pandemic crisis. ${ }^{3,8}$

Considering that, for example, persons with physical impairment already had a weak position in the labour market and significant participation in the services sector and informal employment, this population has been particularly affected by this crisis and will be affected during the recovery period. In Paraguay it was estimated that $40 \%$ of the employed persons with physical impairment lost their jobs during quarantine affecting their livelihood and their families. ${ }^{9}$

In May 2020, an open letter to the United Nations member states, addressed by the Special Rapporteur on the elimination of discrimination against persons affected by leprosy and their family members, brought up the disproportionate impact of the crisis generated by the 
COVID-19 pandemic on PaHd. After several consultations with PaHd and their organizations, the Rapporteur pointed out that $\mathrm{PaHd}$ are structurally excluded from the formal labour market and are struggling to guarantee any income in the context of quarantine and other special measures adopted by countries. ${ }^{10}$

The Working Group 2 Consultative Calls report by the Global Partnership for Zero Leprosy showed that PaHd occupy jobs that are particularly vulnerable to economic instability. As a result, many PaHd are unable to work and their ability to meet basic needs is in severe jeopardy. ${ }^{11}$

Recently, the United Nations Special Rapporteur on the elimination of discrimination against persons affected by leprosy and their family members reported the disproportionate impact of the current pandemic on the access to livelihood of PaHd. Exclusion from the formal economy and barriers to the right to decent work were reported with testimonies that represent a shared pattern of denial of equality of opportunity, as well as denial of equality of treatment. Discrimination, intentional and systemic exclusion are some of the barriers described by the Rapporteur. ${ }^{12}$

The challenge is to deal with the long-term development of promoting inclusive growth, capital accumulation and risk prevention. , $^{3,13-20}$

\section{Strategies to promote and guarantee the inclusion of People affected by Hansen's disease in the labour market}

One of the recommendations from the Economic Commission for Latin America and the Caribbean (ECLAC), for example, is to ensure that measures taken to address the crisis and during the recovery period should incorporate the disability perspective, including measures relating to health, employment protection and educational continuity. Also to ensure the continuity of work and education and the provision of rehabilitation services for persons with physical impairments. ${ }^{9}$

In the context of the crisis response to the COVID-19 outbreak, the International Labour Organization (ILO) maintains a system of international labour standards aimed at promoting opportunities for people to obtain decent and productive work, in conditions of freedom, equity, security and dignity, that focus on a recovery that is sustainable and equitable. ${ }^{21}$ However, due to marginalization of $\mathrm{PaHd}$ and related physical impairments, strategies must be put in place in order to guarantee their right to work; their right to social protection and their right to safe and healthy working conditions against the forces of the inequality already faced by this vulnerable population.

A compilation of recommendations and strategies targeted at different vulnerable and excluded populations that could be also applied to PaHd to reduce the impact of COVID-19, but also to recover from it, follows below.

Ensure meaningful consultation with, and active participation of, $\mathrm{PaHd}$ and their representative organizations in all stages of the COVID-19 response and recovery. PaHd have important contributions to make in facing the crisis and building the future. Many have experience of thriving in situations of isolation and alternate working arrangements that can offer models for navigating the current situation. Their perspectives and experiences can contribute to new approaches and innovative solutions to the challenges. Promoting and sustaining inclusive growth is highly important for a fair and equal nation, therefore, the mainstreaming of PaHd should be ensured in all COVID-19 responses and recovery through systematic inclusiveness. Promote empowerment and equality by establishing accountability mechanisms to ensure 
inclusion in the COVID-19 response. Accessibility should be fundamentally ensured for immediate health and socio-economic responses to the pandemic. PaHd with physical impairment cannot live independently on an equal basis with others in the built environment without accessibility. ${ }^{22,23}$

The ILO four-pillar policy framework has structured key policy messages based on international labour standards for tackling the socio-economic impact of the current pandemic crisis. Pillar 1, stimulating the economy and employment, highlights that fiscal and monetary policies must support employment and social protection. One of the key policies in Pillar 2 is to extend social protection to everyone. Prevent discrimination and exclusion is key for Pillar 3 by enhancing and enforcing laws and policies on equality and non-discrimination in employment. $^{24}$

Permanent social protection systems are indispensable to ensure that people can effectively access health care while supporting job and income security for those most affected. Guarantee their right to work promoting decent work, ensuring education, information implementing policies of inclusiveness and accessibility to end stigma and discrimination. Social dialogue and consultations with social stakeholders are particularly important for a coordinated policy response, including PaHd as co-creators of COVID-19 responses supporting full and effective participation. Work organization and working arrangements need to be accessible and inclusive. Promote professional education and training to provide equal opportunities for PaHd. For workers who have lost their jobs, in the short term, vocational training programs should focus on facilitating access to reskilling or retraining options including familiarization with digital skills and employability competencies. Following this path, the focus should be on equality and inclusion, addressing the needs of vulnerable groups and reversing the widening of the digital divide. Support must be provided for lifelong learning and employability, starting with efforts to facilitate entry into the formal labour market. All together contribute to prevent poverty, unemployment and informality and are powerful economic and social strategies for recovery from such a crisis. A nationally defined social protection foundation, to guarantee access to health care, rehabilitation and a basic level of income security is critical. ${ }^{22-27}$

\section{Acknowledgements}

Dr. Alice Cruz, the United Nations Special Rapporteur (SR) on the elimination of discrimination against persons affected by leprosy and their family members and the Sasakawa Health Foundation.

\section{References}

1 Mahato S, Bhattarai S, Singh R. Inequities towards leprosy-affected people: A challenge during COVID-19 pandemic. PLoS Negl Trop Dis, 2020; 14(7): e0008537.

2 Antunes DE, Goulart IMB, Goulart LR. Will cases of leprosy reaction increase with COVID-19 infection? PLoS Negl Trop Dis, 2020; 14(7): e0008460.

3 van Brakel WH, Sihombing B, Djarir H, Beise K, Kusumawardhani L, Yulihane Ret al.Disability in people affected by leprosy: the role of impairment, activity, social participation, stigma and discrimination. Glob Health Action, 2012; 5(1): 18394

4 World Bank (Washington District of Columbia). Poverty and Shared Prosperity 2020: Reversals of Fortune. Washington: World Bank, 2020.

5 Rao KN, Lakshmi V, Saha K. Undernutrition in lepromatous leprosy, Part I. Is is associated with poverty or with disease? Lepr Rev, 1986; 57(4): 299-309.

6 Feenstra SG, Nahar Q, Pahan D, Oskam L, Richardus JH. Recent food shortage is associated with leprosy disease in Bangladesh: a case-control study. PLoS Negl Trop Dis, 2011; 5(5): e1029.

7 Kazeem O, Adegun T. Leprosy stigma: ironing out the creases. Lepr Rev, 2011; 82(2): 103-108. 
8 Pescarini JM, Strina A, Nery JS, Skalinski LM, Andrade KVF, Penna MLF et al. Socioeconomic risk markers of leprosy in high-burden countries: A systematic review and meta-analysis. PLoS Negl Trop Dis, 2018; 12(7): e0006622.

9 ECLAC. Persons with disabilities and coronavirus disease (COVID-19) in Latin America and the Caribbean: status and guidelines. COVID-19 REPORTS. April 2020.

10 Cruz A. Open letter on COVID-19 and leprosy to the UN Member States. United Nations mandate of the Special Rapporteur on the elimination of discrimination against persons affected by leprosy and their family members. May 2020.

11 Working Group 2 Consultative Calls Report. Persons Affected by Leprosy and the COVID-19 Global Health Crisis. Global Partnership for Zero Leprosy (GPZL). April 2020.

12 Cruz A. Disproportionate impact of the coronavirus disease (COVID19) pandemic on persons affected by leprosy and their family members: root causes, consequences and the way to recovery. United Nations Human Rights Council report of the Special Rapporteur on the elimination of discrimination against persons affected by leprosy and their family members. 2021 .

13 Singh R, Singh B, Mahato S. Community knowledge, attitude, and perceived stigma of leprosy amongst community members living in Dhanusha and Parsa districts of Southern Central Nepal. PLoS Negl Trop Dis, 2019; 13(1): e0007075.

14 Marahatta SB, Amatya R, Adhikari S, Giri D, Lama S, Kaehler N et al. Perceived stigma of leprosy among community members and health care providers in Lalitpur district of Nepal: A qualitative study. PLoS One, 2018; 13(12): e0209676.

15 Staff PO. Correction: Perceived stigma towards leprosy among community members living close to Nonsomboon Leprosy Colony in Thailand. PLoS One, 2015; 10(8): e0135537.

16 Kaehler N, Adhikari B, Raut S, Marahatta SB, Chapman RS. Perceived stigma towards leprosy among community members living close to Nonsomboon Leprosy Colony in Thailand. PLoS One, 2015; 10(6): e0129086.

17 Adhikari B, Kaehler N, Chapman RS, Raut S, Roche P. Factors affecting perceived stigma in leprosy affected persons in western Nepal. PLoS Negl Trop Dis, 2014; 8(6): e2940.

18 Tsutsumi A, Izutsu T, Islam AM, Maksuda AN, Kato H, Wakai S. The quality of life, mental health, and perceived stigma of leprosy patients in Bangladesh. Soc Sci Med, 2007; 64(12): 2443-2453.

19 Shumin C, Diangchang L, Bing L, Lin Z, Xioulu Y. Assessment of disability, social and economic situations of people affected by leprosy in Shandong Province, People's Republic of China. Lepr Rev, 2003; 74(3): $215-221$.

20 Augustine V, Longmore M, Ebenezer M, Richard J. Effectiveness of social skills training for reduction of selfperceived stigma in leprosy patients in rural India - a preliminary study. Lepr Rev, 2012; 83(1): 80-92.

21 ILO. Disability inclusive social protection response to Covid-19 crisis. 09 April 2020.

22 MORHAN. Teachings of the experience with Hansen's disease in the fight against covid. Cadernos do Morhan. June 2020.

23 UN. Policy brief: A disability-inclusive response to COVID-19. May 2020.

24 ILO. Policy brief: A policy framework for tackling the economic and social impact of the COVID-19 crisis. ILO brief. May 2020.

25 ILO. Social Protection Spotlight. Social protection responses to the COVID-19 crisis: Country responses and policy considerations. ILO brief. April 2020.

26 ILO. Policy brief. COVID-19 and the world of work: Ensuring the inclusion of persons with disabilities at all stages of the response. ILO brief. June 2020.

27 ECLAC/ILO. Employment trends in an unprecedented crisis: policy challenges. Employment situation in Latin America and the Caribbean. November 2020. 